\title{
LA PAZ: UNA POSIBILIDAD DESDE LOS NIÑOS Y NIÑAS AFECTADOS POR LA VIOLENCIA EN COLOMBIA
}

\author{
María Cristina Sánchez León ${ }^{1}$ \\ Universidad Pontificia Manizales \\ Laura Isabel López Medina² \\ Universidad de San Buenaventura \\ Irma Lucía Serna Álzate ${ }^{3}$. \\ Universidad de Manizales
}

http://dx.doi.org/10.5209/rev_NOMA.2015.v46.n2.51419

\begin{abstract}
Resumen: En el presente artículo se desarrollan algunas reflexiones frente a las formas en las que niños y niñas narran sus experiencias de violencia, conflicto, paz y reconciliación en el contexto colombiano a partir de un proceso investigativo inscrito en el Programa: "Sentidos y Prácticas Políticas de Niños, Niñas y Jóvenes en Contextos de Vulnerabilidad en el Eje Cafetero, Antioquia y Bogotá: un Camino posible de consolidación de la Democracia, la Paz y la Reconciliación mediante procesos de Formación Ciudadana". En la primera parte se realizará una síntesis de los referentes teóricos que sirvieron como guía para el desarrollo del trabajo investigativo, se describirán los fundamentos epistemológicos y metodológicos utilizados y se dará cuenta de las reflexiones realizadas en torno a ellos. En la parte final, se presentarán los hallazgos parciales del trabajo de campo realizado en la Ciudad de Armenia, capital del departamento del Quindío.
\end{abstract}

Palabras Clave: Niños y niñas. Narraciones. Violencia. Democracia. Paz. Reflexión crítica.

Abstract: This article will develop some reflections about the way boys and girls narrate their own experiences of violence, conflict, peace and reconciliation in the Colombian context from a research project belonging to the program "Senses and political practices of boys, girls and adolescents in vulnerable contexts in EjeCafetero, Antioquia and Bogotá: A possible way to consolidate democracy, peace and reconciliation through processes of civil education". The first part will synthesize the theoretical concepts that served like a guide to carry out the investigation process. Next, the epistemological and methodological foundations used will be described, and the reflections made around them will be reported. Finally, the partial findings product of the field work in the city of Armenia will be presented.

\footnotetext{
${ }^{1}$ Filósofa de la Universidad Pontificia Javeriana, Magister en Historia y teoría del arte de la Universidad Nacional. Investigador Junior, aspirante a doctorado Doctorado en Ciencias Sociales, Niñez y Juventud. Investigadora del Centro de Estudios avanzados en Niñez y Juventud del CindeUniversidad de Manizales.

2 Psicóloga de la Universidad de San Buenaventura. Aspirante a magister de Educación y Desarrollo Humano con el CINDE- Universidad de Manizales. Docente en la Corporación Universitaria Von Humboldt en su facultad Psicología y Psicóloga de apoyo para los niños y niñas con necesidades educativas especiales del Colegio Cámara Junior de la Ciudad de Armenia. Isalópezmedina@gmail.com

${ }^{3}$ Licenciada en Etnoeducación y Desarrollo Comunitario, aspirante a magister en educación y desarrollo humano con el CINDE - Universidad de Manizales. Participación en procesos investigativos con la Universidad Tecnológica de Pereira, Universidad Católica Popular del Risaralda, Unión Temporal Buen Comienzo Había Una Vez. Participación en procesos comunitarios con comunidades indígenas de Chocó y Risaralda en Colombia, y procesos de desarrollo comunitario con comunidades negras del pacífico colombiano. Artículos publicados: "Mundos opuestos, mundos posibles", "De la colonización a la de-colonización del aula de clase".
} 


\section{Introducción}

Una sociedad mejor es una sociedad capaz de tener mejores conflictos. De reconocerlos y de contenerlos. De vivir no a pesar de ellos, sino productiva e inteligentemente en ellos. Sólo un pueblo escéptico sobre la fiesta de la guerra, maduro para el conflicto, es un pueblo maduro para la paz (Estanislao Zuleta, Sobre la Guerra, 1990)

La guerra y el conflicto armado han estado presentes en el mundo de manera histórica, las cifras y los detalles han sido descritos en diversos libros y artículos que, de alguna manera, han intentado romper con una forma de silencio asociada al sufrimiento y la indignación consecuente de ella. Sin embargo -y lamentablemente- también se han instituido, naturalizado y multiplicadonarrativas hegemónicas respecto a este fenómeno;desconociendo las experiencias, conocimientos, necesidades y perspectivas de actores sociales considerados dependientes e inmaduros, como son los niños y niñas, que han sido concebidos como subalternos, sujetos inacabados y han sido invisibilizados y enmudecidos.

El programa "Sentidos y Prácticas Políticas de Niños, Niñas y Jóvenes en Contextos de Vulnerabilidad en el Eje Cafetero, Antioquia y Bogotá: un Camino posible de consolidación de la Democracia, la Paz y la Reconciliación mediante procesos de Formación Ciudadana", cofinanciado parcialmente con recursos del Estado por medio del Departamento Administrativo de Ciencia, Tecnología e Innovación - Colciencias-, y gerenciado por el Consorcio: "Niños, niñas y jóvenes constructores de paz: Democracia, Reconciliación y Paz", conformado por: la Fundación Centro Internacional de Educación y Desarrollo Humano - CINDE -, la Universidad de Manizales y la Universidad Pedagógica Nacional,al problematizar esta realidad, ha venido haciendoun esfuerzo importante en función dereconocer, comprender y difundir precisamente esto que ha sido descartado: las formas en que los niños y niñas construyen y narran su identidad/subjetividad de manera generativa; desplegando procesos de paz, reconciliación y democracia en contextos de conflicto armado.Por esta razón, consolidó el proyectodenominado "Procesos de construcción social de la niñez en contextos de conflicto armado en el Eje cafetero, Antioquia y Bogotá: La paz, la reconciliación y la democracia desde la perspectiva de narrativas generativas de niños y niñas".

\section{¿Cómo es posible proceder cuando se trata de la paz?}

Es laGeneratividad del lenguajelacategoría que en este proyecto se comprende desde el enfoque sistémico, en donde se planteay explora el lenguaje como condición previa del pensamiento y como manera esencial del ser, puesconsidera que el sujeto se encuentra inscrito en el lenguaje y a su vez, es un acto, unaacción (Burr, 1995) y por ello, tiene la capacidad de construir realidades (Echeverría, 
2005), se concibe no sólo entonces como un medio para transmitir y describir la información, sino como un proceso que crea, construye y moldea.

En este sentido, la forma en que el niño-a se narra así mismo y con quienes comparte constituye un eslabón importante para la constitución de su subjetividad y su comprensión, en la misma medida en que ella es reconocida como un mundo posible para la construcción de paz. Hablar de narrativas generativas es también un intento de atravesar los lenguajes descalificantes que invisibilizan al niño o niña, o lo determinan de acuerdo a un grupo específico ("paraco", "guerrillo", "desplazado") y dar paso a sus singularidades. La forma en que ellos y ellas se narran y construyen su propia realidades observar cómo desde allí, construyen nuevas formas propias de ser y estar en el mundo.

Esta investigación no indaga por las narrativas del déficit en la niñez y ello no significa que las niegue, la apuesta de esta investigación es dar cabida a la voz de niños y niñas desde sus potenciales para la construcción de paz, democracia y reconciliación. Para ello se pregunta por esos lenguajes singulares que generan transformaciones en ellos mismos y en los otros, que les permite ver el mundo de una manera específica y a su vez, construir con otros y otras desde apuestas que reconocen la particularidad y también la diferencia, aquellas narraciones desde las cuales pueden desplegar sus potenciales individuales y relacionales para la construcción de paz.

La construcción y proyección de esta investigación se enmarca entonces en una preocupación por la niñez en contextos de conflicto armado pero sobretodo, en el propósito de promover una mirada distinta a las maneras como históricamente se ha dado sentido a la experiencia de la violencia, para dar lugar a los conocimientos, vivencias, necesidades, expectativas, propuestas y lenguajes de niños y niñas.

Rousseau (1972) mencionaba ya hace mucho tiempo, que los niños tienen sus propias maneras de ver, pensar y sentir y no hay nada más insensato que pretender sustituirlas por las nuestras. Si concebimos esta idea como un pilar de comprensión, tomaremos las narrativas de los niños y niñas y las entenderemos como válidas, certeras e importantes, con la posibilidad de ayudar al proceso de paz y no sólo como comentarios aislados, incoherentes o faltos de significancia.

En este sentido,se trata de repensar al niño o la niña no desde el "infans" -el que no habla- o el ausente como lo plantea PhilippeAriés (1987) sino desde el niño y la niña como individuos que construyen y socializan de formas propias, precisamente porque tienen puntos de vista válidos y construidos por sí mismos y por ende, sus propias representaciones (Pazos, 2005) y esas posiciones adoptadas con respecto a las realidades del mundo tienen como consecuencia además, modos diferenciados de sentir y percibir, de actuar e impactar al otro.

Por ende, no sólo son el producto de una dinámica familiar, escolar o social, ni receptáculos de información o imitación de la vida adulta; son partícipes y constructores de estas mismas dinámicas y por ello, se deben entender las prácticas que han instaurado como suyas, en sus voces y existencias. 
Se entiende entonces que niños y niñas, al estar cruzados por mecanismos de socialización, no solamente incorporan hábitos y disposiciones, sino que forman parte de un intercambio dialógico entre el mundo social y por tanto, también producen un mundo cultural, generan procesos sociales y en concreto, prácticas y acciones propias.

Ahora bien, en los últimos estudios e investigaciones, recapitulaciones y búsquedas, se ha empezado a ver un intento de integración más cercana a la infancia y adolescencia como grupos que tienen poder de significación, de dar sentido y construir cultura. Un ejemplo de ello es el estudio desarrollado y denominado como "Escuelas territorios de Paz; construcción social del niño y la niña como sujetos políticos en contextos de conflicto armado" (Alvarado, Ospina, Quintero, Luna, Ospina-Alvarado, Patiño,2012) que se centra en la comprensión de los procesos de construcción de la subjetividad política de la niñez en contextos de guerra, a partir de la ampliación de los marcos epistemológicos, teóricos, metodológicos y semánticos desde los cuales se ha pensado tradicionalmente al sujeto y su desarrollo humano.

Esto quizás se deba ala necesidad de un cambio de paradigma en palabras de Kuhn (1971) en donde se considere la niñez no sólo como un preámbulo o una estación por lo cual se debe pasar para ser alguien, sino donde previamente se es alguien con capacidad y potencial transformador, sujetos con oportunidad de progreso, de enseñar y de modificar al otro.

En coherencia con la apuesta de paz y la comprensión de las formas distintivas de pensar y construir prácticas sociales de los niños y niñas, se toma como perspectiva orientadora el método hermenéutico y en consecuencia, no hay pretensión de explicar de manera unilateral el fenómeno que se estudia ni controlar los hechos que aquí se enuncian, no hay intención de generar una verdad absoluta, sólo existe elpropósito de darle voz a quienes han sido callados durante tanto tiempo y a través de esto, comprender desde esta alternativa, un lado de la verdad que se había sumido en la oscuridad.

El enfoque histórico-hermenéutico reconoce la imposibilidad de prescindir del componente subjetivo en la producción del conocimiento, por cuanto todo proceso de construcción de éste, parte de individuos con consciencia, que interpretan la realidad y la transforman en función de sus propias historias personales, sociales y culturales que los caracterizan (Alvarado \& Ospina, 2008).

La hermenéutica se aleja de la intención de configurar un conocimiento universalista eurocéntrico y de la perspectiva positivista que ha buscado que los estudios sociales sean absorbidos por un lenguaje matemático e inflexible, en que se anula al individuo en su expresión espontánea y constructivista que lo caracteriza (Salcedo, 2012; Gaeta, Gentile\& Lucero, 2007). La hermenéutica, como lo refiere Gadamer (1977), no tiene un único método correcto, pues antes que un asunto teórico, la comprensión es una actitud práctica, en este caso, un movimiento que implica ir haciendo con los niños y niñas la investigación, ir descubriendo y construyendo a la par con ellos y no imponer sencillamente, los resultados de su propia historia. 
La clave de la hermenéutica es la construcción de sentido y en este proceso, tanto el lenguaje como la historia juegan un papel de gran relevancia (Vasco, 1994). Esta investigación busca entonces, la construcción de sentidos en relación con una realidad situada y en este caso particular, avanzar en niveles de comprensión acerca de los modos como los niños y las niñas que se han socializado en contextos de violencia construyen sus subjetividades y qué posibilidades se encuentran allí en términos de recursos o potencias que pueden romper con lógicas de la guerra.La potencia argumentativa, investigativa y por supuesto, narrativa, del hecho de atender a las voces de niños y niñas, hace que la búsqueda de sentido sea para ellos una puerta de acceso a una vida sana y feliz. Narrar, narrarse, contar su historia, expresar lo que son, permite hallar en estos eventos creativos, modos de crearse y recrearse, haciéndolos capaces de imaginación, de iniciativa y de reconocimiento, capacidades que sin duda forman parte del horizonte ético y político de cualquier ser humano.

En este proyecto se ha optado entonces por el análisis de narrativas desde una perspectiva generativa, a partir de la construcción de relatos construidos en la implementación de técnicas participativas como talleres creativos, entrevistas y grupos focales con niños y niñas y sus agentes relacionales. Una vez hechas relato, se organizan de acuerdo a categorías, algunas de ellas intencionadas y otras emergentes -que nacen del proceso investigativo y de las voces de los participantes- y que tienen relación con la paz, la democracia y la reconciliación.

Los niños y niñasse encuentran entre los 8 y los 12 años de edad, son estudiantes de instituciones educativas en las regiones de aplicación de la investigación y con algún tipo de afectación a causa del conflicto armado en Colombia (desplazamiento, amenazas, asesinato de familiares, entre otros) y sus familias y agentes educativos, fueron las personas con quienes se aplicaron las técnicas mencionadas. En este caso, se hace énfasis en la población seleccionada en la Ciudad de Armenia, Quindío, en una institución pública ubicada en la comuna dos de ella.

Los instrumentos para la recolección de información fueron diseñados a lo largo del año de trabajo 2013 con la participación de un equipo interdisciplinario integrado por diversos profesionales de la educación, la psicología, la filosofía, el trabajo social. Respondiendo a criterios de validez interna; se realizó una prueba piloto en cada una de las tres regiones en que se desarrolla la investigación y posteriormente se sometieron a un ejercicio de juicio interno realizado por pares investigadores.

\section{La Subjetividad y Socialización política en niños y niñas: Potencias olvidadas.}

Es importante aclarar que en un sentido amplio, en el marco general de esta investigación, se parte de los marcos conceptuales atenuados por una perspectiva crítica de las ciencias sociales en la que se incluyen diversas posturas disciplinares como: sociología del conocimiento, economía, la filosofía política, el psicoanálisis crítico, el construccionismo social, la teoría de la complejidad, la 
teoría sistémica para abordar los contenidos y formas objetivas y subjetivas de la identidad de la niñez.

En este sentido, se entiende por subjetividad aquellos sentidos que cada individuo concibe, interpreta, trasforma y construye de sí mismo, las maneras como decide estar en el mundo, las múltiples formas de pensarlo y pensarse y a su vez, la apropiación de eso que vive, siente y de lo que hace parte. Como refiere Ospina (2013) subjetividad es aquello que hace diferente a una persona de otra.

Identidadretomando a Castells (2003) puede ser entendida como la construcción de sentido de un individuo en la que se atiende a uno o varios atributos culturales y representa a su vez, su autodefinición. Estos sentidos y construcciones no surgen a partir de suindividualidad, sino como lo plantea Burr (opcit) la identidad y la subjetividad se construyen socialmente a partir de elementos culturales como el lenguaje, las disciplinas científicas y los discursos ideológicos y por tanto no son independientes de la relación que se tiene con otros en un contexto sociocultural específico, al contrario, son interdependientes.

Como lo dice Bruner (2004) no hay una subjetividad independiente de la existencia histórico cultural propia y por tanto, no hay subjetividad sin que exista la presencia del otro.La construcción de subjetividades e identidades desde esta perspectiva tienen directa relación con ellenguaje, como posibilidad de acción, interpretación, construcción, revelación y cambio de la realidad, basados en la idea de que la manera cómo vamos relatando nuestra realidad y a nosotros mismos tiene un poder transformador amplio, que logra impactar de diferentes formas en las prácticas y sentidos que dan forma a la existencia social.

Ahora bien, curiosamente cuando se escucha hablar de identidad, se relaciona esta categoría con una especie de adscripción definitiva de quien se es, como una suerte de certeza de nombre, género, nación, etc; de tal manera que "tener identidad" muchas veces es asumido como un modo invariable o incambiable de ser. La lógica de identidad y de subjetividad que aquí adquiere toda la importancia, es la que corresponde al resultado de las relaciones entre seres humanos diferentes y diversos, que habitando el mundo intersubjetivo, adquiere e internaliza la experiencia de otros, como parte de si mismo. La identidad como se ha entendido en la investigación, constituye así el movimiento que se genera entre un narrador en ejercicio y la configuración de su relato de vida, como vida con otros. La subjetividad es un estar dando sentido al mundo, la identidad, es ese trabajo inicial de reconocimiento entre las cosas, entre el mundo, entre los otros.

El lenguaje entonces se entiende con una capacidad performativa, no sólo como una constelación de sonidos o grafemas, sino como un sistema de símbolos (Gergen, 2007), de acción (Burr, opcit; Echeverría, opcit) y por tanto con implicaciones generativas en donde a través de actos comunicativos se da la apertura para construir significados (Anderson \&Goolishian, 1991) y por medio de estos actos de habla se van generando consecuencias sociales (Gergen, 1996).

Quiere decir eso que las identidades y subjetividades no son concebidas como elementos estáticos e inamovibles, sino como construcciones socio históricas ubicadas en un sistema amplio de relaciones (Gergen, 2007), de prácticas 
culturales (Bruner, opcit); comprendidas a la luz de las relaciones y agentes de socialización en las que el niño y la niña se apropian de un mundo y en donde se forman la idea de sí mismos y de los demás.

Ahora bien, abordar el tema de la construcción de paz en niños y niñas, implica necesariamente deconstruir visiones de mundo y de realidad tradicionales que han entendido a los y las menores como seres incompletos, inconclusos, en proceso de llegar a ser, cuyo futuro está enmarcado por su adultez y no por lo que ya es. Estas formas de asumir a los niños y a las niñas, han sido revaluadas en los últimos tiempos, pues no permiten entenderlos-las como sujetos con capacidad de agencia, capaces de construir y transformar su entorno, y por lo tanto, con potenciales para la paz.

La idea entonces es ir superando las miradas evolutivas en torno a la niñez, planteadas por la biología y la psicología tradicional, que entienden que el niño y la niña alcanzan su máximo desarrollo en la edad adulta, gracias a un proceso progresivo de fases o etapas madurativas y en cambio, empezar a entenderlos como sujetos activos y moldeadores del entorno social. (Alvarado, et al, opcit). En donde sus narraciones también implican posibilidades de acción, de transformación y de innovación.

Tampoco es posible hablar de las potencias de niños y niñas para la construcción de paz, si nos limitamos a miradas economicistas, que ven la primera infancia como una fase en la que es necesario asignar recursos para garantizar mayores retornos sociales (Política Pública Nacional de Primeralnfancia“Colombia por la primera infancia", 1994) ya que se entiende esta etapa del ser humano, como determinante para la estructuración del futuro adulto. Esta postura no incluye las posibilidades que tienen los niños y niñas para construir su propia realidad e interactuar con el mundo que les rodea y sigue ligada a una concepción que ve la niñez como un momento previo a la madurez del ser humano.

Hay que empezar a tener en cuenta entonces, conceptos desarrollados al margen de la clásica mirada restringida de la niñez, como los acuñados por Martha Nussbaum (2007) acerca de las capacidades de los seres humanos, las cuales son entendidas como la repuesta a la pregunta sobre qué es capaz de ser y hacer una persona. Se trata de considerar que los seres humanos deben desarrollar unas capacidades mínimas para considerar que su vida es digna y entender que cada persona es un fin en sí mismo. El despliegue de capacidades entonces, no depende de si se es hombre o mujer, niño o anciano, es inherente a una vida digna. Los niños y niñas son un fin, necesitan potenciar sus capacidades y pueden hacerlo, no son seres en proceso de formación, son seres humanos que merecen una vida digna, interactúan con su entorno y pueden transformar su realidad.

Entender a los niños y niñas más allá de un estado constante de vulnerabilidad y riesgo (por género, desigualdad social, utilización como mano de obra barata, reproducción de prácticas violentas, entre otros), implica comprenderlos como sujetos activos de su propio desarrollo, con capacidad de ser, hacer y estar en el mundo, preparados para construir con los otros y desplegar sus potenciales para la paz. 
Por esta razón, se retoma la propuesta de socialización política y formación ciudadana, desarrollada por el Centro de Estudios Avanzados en Niñez y Juventud desde hace 16 años, es decir al programa "Niños, Niñas y Jóvenes Constructoresas de Paz" ${ }^{4}$, desde el cual se asumen cinco potenciales humanos para la paz: el potencial afectivo, desde el cual se busca entender los sentimientos, emociones y pasiones que las personas somos capaces de expresar en el día a día; el potencial ético, que implica la responsabilidad y la conciencia de preguntarse por los demás; el potencial político, que tiene que ver con la capacidad para pensar colectivamente y realizar acciones orientadas al bien común; el potencial creativo para la transformación de conflictos, desde el cual es posible la utilización de la imaginación para tramitar los conflictos de una forma diferente a la violencia y el potencial comunicativo, a través del cual se fortalecen los procesos de diálogo intersubjetivo, desde una asertividad que permita la construcción de acuerdos por el bien común.

Los potenciales asumidos por el programa "Niños, niñas y jóvenes constructores de paz", se constituyen en la base para comprender que es necesario escuchar y tener en cuenta las voces de los niños y niñas para la creación de nuevas alternativas que les permitan una vida más digna. De igual forma, el ejercicio de estos potenciales permite reconocer y comprender las formas en que los niños y niñas despliegan en su cotidianidad procesos de paz, reconciliación y democracia, lo cual constituye uno de los objetivos de esta investigación.

Estos potenciales están enmarcados en la concepción de la imposibilidad de renunciar a ser seres humanos dignos, para lo cual es necesario desplegar unos potenciales que permitan fortalecer el autoconcepto; valores como el respeto, la justicia y la responsabilidad; la capacidad de comunicarnos con otros, la posibilidad de entender el lenguaje como una forma de construir realidades; la transformación del conflicto desde el despliegue creativo que permita la diferencia y la capacidad de participación política.

Por otro lado, la socialización -concepto inseparable de la subjetividad- es ese proceso permanente que permite a los sujetos internalizar y construir la realidad (Berger y Luckmann, 1968) y que implica la construcción y deconstrucción constante de significados, prácticas y sentidos, tanto de forma individual como colectiva. Es un proceso que está presente durante toda la existencia y que ayuda a configurar nuestra forma de ser y estar en el mundo.

Los niños y niñas, (al igual que los demás seres humanos) están todo el tiempo inmersos en procesos de socialización, esto les permiten configurar su realidad a través de la vida cotidiana (Berger \&Luckmann, opcit), no sólo desde la apropiación de la cultura, sino también desde la producción de su propia historia. A partirde la interacción con sus pares, familiares y demás personas presentes en su cotidianidad, y con lo otro no humano que hace parte de su mundo; los niños y niñas ven surgir su dimensión política en medio de ese entramado de relaciones en las que se ven inmersos, y desde las cuales pueden construir un "entre nos"

\footnotetext{
${ }^{4}$ Para mayor información de esta propuesta educativa, visitar: http://ceanj.cinde.org.co/
} 
que les permita la acción, lo que en términos arendtianos, posibilita el despliegue de la política en los seres humanos (Arendt, 1997)

En la cotidianidad los niños y niñas despliegan su subjetividad política, y a través de ella, generan acciones para apropiarse del mundo, comprenderlo, actuar en él, pensarlo y tomar decisiones sobre su forma de habitarlo y por ende, realizan su socialización política en escenarios como la escuela y la familia.

En estos espacios se posibilita que niños y niñas interactúen con otros y otras, con su entorno, empiecen a accionar sobre su mundo y su realidad, que se reconozcan desde la constitución de su propia identidad y su propia historia y es en estos escenarios donde existe la posibilidad de entablar diálogos intersubjetivos desde los cuales reconozcan la diferencia y comprendan el conflicto cómo constitutivo del ser humano e incentivar la imaginación para tramitarlo de forma pacífica.

Por este motivo, es importante que todos los escenarios en que surgen procesos de socialización política en niños y niñas, estén cargados de elementos que motiven no sólo la interacción, sino también la reflexión sobre los otros, lo otro y las relaciones presentes en la vida cotidiana (Berger y Luckman, 1983). para generar apropiaciones del mundo que conlleven al bien común y permitan la apertura a la diferencia, el reconocimiento de la historia, la representación de las resistencias y las formas diversas de comprender el mundo.

Ahora bien, si se asume que la realidad es producto de tres momentos: la externalización, desde la cual se entiende la sociedad como un producto humano; la objetivación, que permite entender la sociedad como una realidad objetiva; la internalización, que entiende al hombre como un producto social (Berger y Luckman, 1983). Los niños y niñas viven estos tres momentos en su cotidianidad, y desde allí se apropian del mundo, construyen su realidad. Estos procesos les permitenconstituirse como sujetos, desde una interacción con la sociedad, con otros y otras, con el mundo.

Por ende, a mayores estímulos que potencien la reflexión sobre la sociedad, su entorno inmediato, las personas con quienes interactúa; mejores van a ser las comprensiones de la realidad que hagan los niños y niñas y las transformaciones van a estar encaminadas a una vida digna, no solo para sí mismos, sino para quienes les rodean. En otras palabras, en la medida en que los procesos de internalización, objetivación y externalización se den en medio de estímulos que permitan el despliegue de potenciales humanos, la realidad producto de ellas, va a estar cargada de potenciales para la construcción de paz.

Además, la socialización política en niños y niñas colombianos, tiene una característica adicional y es precisamente el hecho de estar siendo atravesada por lógicas de la guerra y del conflicto armado, desde las cuales se instauran violencias que invisibilizan sus voces y los lleva en ocasiones a construir su subjetividad desde el miedo y/o la venganza (Sierra, Lozano, Guerrero, \& Salamanca; 2009). Por ello se hace imprescindible constituir escenarios de socialización política que permitan la emergencia de lo afectivo y les ayude a deconstruir las narraciones absolutistas que les imposibilitan la acción y la 
interacción con los otros. Se requiere de escenarios que dejen a un lado la visión de niños y niñas desde la carencia, y los entiendan como sujetos con potenciales, capaces de transformar el mundo.

La socialización Política puede ser entendida también como "La autoproducción del sujeto en subjetividad y su identidad, en contextos conflictivos de la vida cotidiana, a través del fortalecimiento de sus capacidades, el reconocimiento de sus titularidades $y$ el agenciamiento de oportunidades en procesos intersubjetivos". (Alvarado y Ospina, 2009: 56) y no puede darse sino a través de diferentes procesos, agentes, escenarios y condiciones.

Entre los agentes de socialización de alta importancia en la vida contemporánea como los medios de comunicación masiva y las Nuevas Tecnologías de la Información y la Comunicación -NTICs-, sigue siendo relevante el lugar que ocupan la familia y la escuela, entre otras cosas, por la carga afectiva que atraviesa gran parte de los aprendizajes que allí se construyen y que impacta de modo profundo las subjetividades de los niños y las niñas y el universo cultural en el que cobran vida las relaciones sociales que allí tienen lugar.

Por ello se requiere una perspectiva orientada desde las potencias y no desde las carencias; no centradas en lo que el niño no es capaz de lograr sino en aquello que es capaz de ser, hacer, crear y narrar.

\section{Develando a los niños y las niñas en sus potencialidades.}

A continuación se evidencian algunos resultados parciales del proyecto que se ha venido desarrollando en el eje cafetero y se expone especialmente cómo la escuela y la familia siguen siendo prioritarios como agentes de socialización y se encuentran mediados por un alto componente afectivo. Además, siguen impactando en la legitimización de la cultura y se constituyen como escenarios fundamentales para la construcción de paz.

\section{La familia como base para expandir los potenciales humanos.}

La familia, a pesar de las transformaciones socioculturales a las que se ve expuesta ${ }^{5}$, es un importante escenario de socialización a través del cual niños y niñas logran desarrollar potenciales humanos para la construcción de paz ${ }^{6}$. Es así

\footnotetext{
${ }^{5}$ Las transformaciones de la familia en la época actual, son producto de las dinámicas propias de la globalización, los contextos de pobreza, el conflicto armado y la violencia, las cuales la han llevado a dejar de ser la familia nuclear tradicional, conformada por mamá, papá e hijos, determinada exclusivamente por lazos de sangre, para pasar a ser una institución familiar con relaciones diferentes, en la que los miembros que la integran están establecidos no solo por el parentesco sino que también entran a jugar otras circunstancias del contexto, y en la que los roles que desempeña cada uno de sus integrantes se modifica de acuerdo a las necesidades. Las transformaciones de la escuela también son producto de las dinámicas propias de la sociedad actual, que obligan a la escuela a modificar sus ámbitos de relación con el conocimiento y las construcciones sociales que desde allí se potencian.

${ }^{6}$ Estos potenciales son desarrollados por el programa Nacional de Niños, Niñas y Jóvenes constructores de paz, que se convierte en una apuesta para la reflexión en torno a las
} 
como en algunas situaciones, gracias a pautas de crianza y procesos de interacción que se viven al interior de la familia, pueden ser derivadas enseñanzas directas, como lo dice una de las madres "A mi hija le gusta mucho compartir, es muy generosa para dar [...] yo siento que mi hija ha aprendido eso de mí y eso me gusta", o producto de procesos de socialización en los cuales niños y niñas expresan sus emociones y afectos de variadas formas "Cuando son los días especiales, ella sabe que platica no hay, entonces ella hace una carta, ella trae una banana, da un abrazo, da una palabra de aliento, ella es muy cariñosa". Esta forma en que los niños y niñas son narrados por sus familias, nos permite comprender como lo dice Echeverría (opcit) la forma en que enfrentan la vida, y por ende, sus apuestas para la construcción de paz. Permite que ellos y ellas se sientan acogidos y valorados, lo cual les ayuda a desplegar sus potenciales afectivos. De allí que la potencia ética y política de los testimonios, de las narraciones, de esos micro-relatos que hacemos de los niños y niñas como agentes, permitan entrever la naturaleza del cambio en un agenciamiento moral real.

Pero estos procesos de aprendizaje no les permite solo demostrar el afecto, también posibilitan que ellos y ellas desplieguen sus potencialidades para relacionarse con otros y lo otro, desde acciones concretas de paz, tales como la solidaridad "el niño así tenga una bananita, se la lleva, se preocupa mucho por las personas", la capacidad de compadecerse por el sufrimiento de otros "cuando estoy con el ánimo bajo ella me dice, má no se preocupe que las cosas nos van a cambiar, [...] me da esperanza", el respeto por la vida de los animales "Que día se cayó una lagartija al tanque y allá fue a sacarla, que pesar y ella dice: que rico estar uno con todos los animales". Se reafirman entonces los planteamientos de Gergen (2007) en cuanto a que los modos de habla sobre uno mismo y sobre los demás tienen consecuencias sociales, en este caso, la manera en que la familia habla del niño-a repercute de forma directa en la forma en que ellos y ellas interactúan con su entorno, no solo al interior de la familia, sino también en actos cotidianos hacia las personas con quienes comparten, como lo afirma una de las madres "si en la casa nosotros tenemos un platico de comida y ella se da cuenta que el vecino no tiene, ella va y me dice: mami sáqueme un poquito para llevarle el resto a la señora"

En la familia, los niños y niñas también fortalecen su potencial ético relacionado con la capacidad moral en tanto tienen la posibilidad de compadecerse con el otro y entenderlo como aquel que hace un esfuerzo importante por vivir, entonces se permiten brindar consuelo y aportar de variadas maneras al bienestar de los otros, como se puede evidenciar en una carta escrita por uno de los niños a su madre "Hola amor, yo sé que tú te sientes mui aburrida, ya sé que abesestelindes[...] yo no te boy a dejar sola, se que te sientes sola pero sola no estas, estas con migo yo no te boyadejar sola". En esta narración y siguiendo a Gergen (1996) cuando afirma que las realidades se construyen a partir del lenguaje, es posible evidenciar que los niños y niñas dan forma a su realidad a partir de narraciones en las que el

subjetividades políticas desde las potencias de niños, niñas y jóvenes, y no desde las carencias. (Ospina, Echavarría, Alvarado \& Arenas, 2002). 
otro cuenta y es importante, hace parte de la propia subjetividad "estas con migo" y desde allí proyecta un porvenir "yo no te boyadejar sola". Los niños se comprenden en relación con otros y otras, con su entorno, y construyen su realidad de forma interrelacional; como lo plantea Burr (opcit) constituyen su identidad y subjetividad socialmente.

Estás prácticas de crianza que se pueden vivir al interior de la familia están también encadenadas a la capacidad de resiliencia y resignificación que tienen las mujeres impactadas por la violencia en Colombia, la cual les permite sobreponerse a situaciones adversas, interesarse por ser buenas madres y pensar en cambiar las condiciones para el futuro de sus hijos "Señor si usted me llega a dar hijos, yo voy a hacer que ellos vean un mundo que yo no pude ver y que tengan otras ideas", haciendo realidad lo planteado por Anderson \&Goolishian (opcit) de generar nuevos significados sobre su realidad, que a su vez tienen consecuencias sociales, en este caso, para los niños y las niñas.

La resiliencia, entendida como esa capacidad del sujeto para sobreponerse a situaciones difíciles, o en palabras de Cyrulnik "crear, en circunstancias desfavorables o en un entorno destructor, respuestas que le hacen posible no dejarse atrapar por las circunstancias y dificultades personales ni por las condiciones del entorno" (2006, p. 213), se evidencia cuando otra de las madres refería "ya que yo no tuve ese amor cuando estaba niña y me encantaría darle amor a cualquiera, al que me brinde una amistad lo podría hacer parte de mi como si fuera mi familia cierto, la familia que yo no tuve cuando era niña" y en este mismo sentido, la resiliencia facilita las prácticas de crianza a través de las cuales logran enseñar a sus hijos nuevas formas de transformar los conflictos y de otorgarles un sentido y significado diferentes:

"Cuando el terremoto otro golpe, y el niño: - mamá por qué tiembla la tierra?

- y yo: ah, porque esta brava. - y él: y por qué ma?

- y yo: ah porque matan mucho la gente y ya. - ma, dónde vamos a dormir?

- papi nos vamos a hacer un cambuche.

Una vez el cambuche se lo elevó el viento, se lo llevó, entonces el niño me dice:ma, bonitas las estrellas"

Esta narración demuestra lo que plantea Gergen (1996) en torno a que la realidad se construye a partir de consensos sociales. Sin embargo, hay que asumir que el consenso social no es sólo y estrictamente el acuerdo hecho a partir de vínculos, instituciones o pactos reconocidos a nivel normativo o estatutario, también el consenso social, nace y aparece por vínculos de afecto, solidaridad y hospitalidad que de modo tácito circunscriben una acción moral, cualquiera que sea. El primer escenario de socialización para el niño-a (como ya se ha dicho) es la familia, entonces es en éste escenario donde se dan los primeros consensos sociales, que en el caso de la narración anterior, parten de la resiliencia y se constituyen en una práctica cultural para el niño, aportando a su construcción subjetiva.

Es así como niños y niñas, acompañados por sus madres, logran tomar la actualidad como una oportunidad para cambiar y sanar situaciones que han sido 
difíciles en cuanto a que tienen una carga emocional que hiere y lastima, resignificando su presente y decidiendo cómo ser, en palabras de Cyrulnik (opcit, p.50) "Yo soy aquel que conoció tal adversidad, sufrió de tal manera y supero ese infortunio de este modo"

Desde esta resignificación de su realidad, las familias reconocen acciones concretas de sus hijos e hijas en torno a la construcción de paz, como lo relata una de las madres "cuando [mi hijo] ve peleas de los amigos va y los separa", otra madre añade "con la verdad, ...ella les demuestra a ellos que es sincera, evita que haya conflictos dialogando", como lo plantean Alvarado et al (opcit), los niños y niñas se convierten en moldeadores del entorno social. Esto permite que las familias vean en los niños y niñas un despliegue de potenciales "se da cuenta de que la hija de uno tiene muchos valores, como que a pesar de todas las cosas que han pasado y eso es lo único que no les han podido como arrebatar", lo cual permite que instauren pautas de crianza cotidianas que ayudan a fortalecer aún más ese papel de la familia como nicho para la expansión de los potenciales humanos y como lo plantean Alvarado y Ospina (opcit), constituirse en un escenario de socialización política que permita el fortalecimiento de las capacidades de los niños y niñas.

A pesar de las violencias que afecta a la niñez como consecuencia del conflicto armado, es posible que desplieguen sus potenciales para la construcción de paz, si su familia se convierte en un escenario para su fortalecimiento. Imitar acciones positivas, replicar comportamientos solidarios, utilizar expresiones de afecto, son aprendizajes que atraviesan la cotidianidad de los niños y las niñas y tienen su principal fuente en la familia, como lo narra una de las niñas "mi mamá dice tenemos que hablar, porque a los gritos no se resuelve nada."Después agrega"uno debe resolver hablando, no gritando, ni tratándose uno verbalmente mal, eso no es así", entonces el lenguaje como lo plantean Burr (opcit) y Echeverría (opcit) se convierte en un sistema de acción, generando en el niño-a nuevas formas de relacionarse e interactuar con los otros.

El papel de la familia como escenario fundamental de socialización no puede ser invisibilizado por las dinámicas globalizantes del mundo actual. Es necesario resignificar las acciones cotidianas que se viven al interior de este espacio y desde allí, expandir en niños y niñas los potenciales humanos para la construcción de paz.

\section{La escuela, un escenario que nombra y permite.}

Por otro lado, dirigiendo la mirada a la escuela como un escenario posible, en el que los maestros tienen el poder de nombrar y reconocer a los niños y niñas, pero también de permitir desarrollar, fortalecer y expandir las potencias de cada uno de ellos, hay una suerte de luz que logra evidenciarse.

Quedan develados algunos rasgos de maestros y maestras que promueven la construcción de una escuela como espacio de socialización para la paz; su capacidad de auto cuestionarse, indignarse por situaciones de injusticia, preguntarse por la realidad de los niños y niñas, por el papel del Estado y de la 
escuela, por sus propias acciones frente a la vida. Manifiestan su frustración y preocupación por el futuro y la realidad que se entreteje alrededor de niños y niñas, con narraciones como

"muchos chicos de los que tienen un historial violento de aquí, me ha tocado firmar una resolución en donde se diga que el niño se va porque no somos capaz de tenerlo en el colegio, y eso a mí, me genera una frustración grandísima"

Relatos que son reforzados por otros maestros, afirmando "lo digo como alguien que intenta vivir el trabajo docente como por gusto, $y$ entonces uno se siente tan inútil, se siente tan manicruzado que uno dice icarajo!"

Los maestros y maestras enuncian una necesidad de trascender lo meramente académico, la incongruencia de lo que desean y de lo que se les exige

"entonces tengo que mantener a unos niños que académicamente me den resultado; a nivel directivo, tenemos cantidad de compañeros docentes que por vocación cumplen con su trabajo, otros simplemente dan su clase y ya, entonces hay momentos en que unose siente tan insatisfecho en ese sentido, entonces uno dice: esto no es lo que yo quiero"

Expresan la urgencia que sienten porque desde el ámbito educativo se dé una mirada diferente a los niños y niñas que se han visto afectados por las violencias del conflicto armado, no solo desde el asistencialismo, sino desde la preocupación real por su integridad y desarrollo:

"Yo tengo que apuntar en total es ese número, porque aquí hay que responder a números [...] Entonces se trata sólo de llevar un dato; de vez en cuando es porque se deben tener en cuenta para lo del restaurante, listo, pero se llega hasta ahí. Pero yo sí siento que es necesaria la toma de consciencia de quienes estamos metidos en el mundo educativo frente a una realidad que hace parte de nosotros"

Se descubre entonces un desacuerdo ante las políticas actuales de gobierno. Maestros y maestras muestran que cuando el individuo reflexiona, va formándose a sí mismo y va constituyendo una consciencia de lucha por transformar la realidad y liberarse de la opresión, pues cuando se adquiere una forma de pensar nueva, esta contribuye a modificar el entorno en el que se desarrolla (Freire, 2005)

En el mismo sentido, en la Escuela también se hace presente la esperanza y en ocasiones toma forma de narración en el maestro:

"Uno ve que se habla tanto de estos procesos y diálogos de paz y uno dice bueno, qué rico que se vayan abriendo otros canales, cuándo será que podremos ver que cesa todo este conflicto y con el deceso del mismo se acabarán tantas muertes, se van a acabar tantas situaciones donde se ultrajan a tantas personas en esta realidad que vive Colombia desde hace tanto tiempo"

Y esta esperanza también se materializa, por lo cual se instauran prácticas pedagógicas intencionadas y dirigidas no sólo a caracterizar el contexto, los niños y las niñas, las necesidades situadas, sino también (sobre todo en las jornadas complementarias) a proteger, respaldar y promover las capacidades, potencias, habilidades, y el potencial afectivo, con actos sencillos que permiten provocar 
espacios para compartir, encontrarse con el otro y lo otro, construir juntos, y crecer.

Las familias, reconocen en la escuela un escenario importante para que sus hijos e hijas desplieguen sus potenciales, la ven como un espacio necesario para el encuentro con el otro y lo otro, para construir y transformar, como lo afirman algunas madres "a mí me gusta que desde que la niña está en este colegio ya no está tan solita", "lo bueno es que uno sabe que en el colegio le enseñan a compartir y ser solidaria". Otra madre añade "cuando vienen a esos grupos por la tarde se divierten mucho, la mía ya aprendió a reciclar y todo".

La escuela deja de ser entonces el espacio exclusivo para el aprendizaje académico, familias y maestros la reconocen como un espacio para la socialización, para aprender a convivir y construir paz.

En suma, hablar de la infancia no sólo implica dar voz, sino que equivale a reconocer sus derechos, desandar esa senda en la que la educación ha sido vista como el camino hacia la vida de adulto y el niño ha sido juzgado como un adulto en potencia, incompleto, cargado de futuro pero no de realización, y precisamente volver a la pureza de la consciencia; el hombre como discípulo del niño. Como dirá Michael Tournier en Rousseau (Opcit), debemos estar, a no dudarlo, ante una nueva invención de la infancia: El niño está formado; es su propia meta.

\section{REFERENCIAS:}

(2009)Alvarado, Sara, Ospina, María Camila. Contexto teórico para la reflexión sobre la socialización política. En: Tonon, G. . Comunidad, participación y socialización política, Compilación. Buenos Aires: Espacio Editorial.

(2008) ALVARADO, Sara. Ospina, Hector. Botero, P. Muñoz, G. (2008) Las tramas de la subjetividad política y los desafíos a la formación ciudadana en jóvenes. Revista Argentina de Sociología, año 6 \#11

(2012) ALVARADO, Sara. , OSPINA, Hector, QUINTERO, Marieta., LUNA, María Teresa., OspinaAlvarado, M. C. Patiño, J. Las escuelas como territorios de paz. Construcción social del niño y la niña como sujetos políticos en contextos de conflicto armado. Buenos Aires:Clacso.

(1991) ANDERSON, Harlene, \&GOOLISHIAN, Harold. Los sistemas humanos como sistemas lingüísticos: implicaciones para la teoría clínica y la terapia familiar. Revista de psicoterapia, Vol. 2, №. 6-7, 1991 , págs. 41-72.

(1997) ARENDT, Hannah. ¿Qué es la política? Barcelona, Paidós.

(1987) ARIÉS, Phillipe. Capitulo II: El descubrimiento de la infancia. En: El niño y la vida familiar en el antiguo régimen. S.D.: Taurus ed.

(1983) BERGER, Peter. \& LUCKMANN, Thomas. La Construcción Social de la Realidad. Buenos Aires: Amorrortu. 
(1968) BERGER, Peter. \&LUCKMANN,Thomas. Los fundamentos del conocimiento en la vida cotidiana. En La construcción social de la realidad (pp.36-65) Buenos Aires: Amorrortu editores.

(2004). BRUNER, Jerome. Realidad mental y mundos posibles: los actos de la imaginación que dan sentido a la experiencia. Barcelona: Gedisa.

(1995). BURR, Vivien. (1995).An introduction to Social Constructionism. London and New York: Routledge.

(2003)CASTELLS, Manuel. La era de la información. El poder de la Identidad, 2(4). México: Siglo $\mathrm{XXI}$

(2006) CYRULNIK, Boris. La resiliencia: desvictimizar la víctima. Editora Feriva, Cali.

(2005) ECHEVERRÍA, Rafael. Ontología del lenguaje. Santiago de Chile: Lom ediciones S.A.

(2005)FREIRE, Paulo. La pedagogía del oprimido. México: Siglo XXI editores.

(1977) GADAMER, Hans-Georg.Verdad y Método. Volumen 1. Salamanca: Ediciones Sígueme.

(2007) GAETA, Rodolfo et al. Aspectos críticos de las ciencias sociales: entre la realidad y la metafísica. Buenos Aires: Eudeba

(1996)GERGEN, Kenneth. Realidades y relaciones: aproximaciones a la construcción social. Meler, F. (Trad.). Barcelona, Buenos Aires: Paidós.

(2007) Gergen, Kenneth. Estrada, A. M. y Diezgranados, S. comp.Construccionismo social aportes para el debate y la práctica. Bogotá: Universidad de los Andes.

(1971) Kuhn, Thomas. La estructura de las revoluciones científicas. México: Fondo de Cultura Económica.

(2007) NUSSBAUM, Martha. Crear capacidades. Barcelona: Ediciones Paidós Ibérica, S.A.

(2002) OSPINA, Héctor.; ECHAVARRIA, Carlos. ; ALVARADO, Sara y ARENAS, Julio. Formar para la paz en escenarios educativos: manual de educadoras y educadores. Manizales: Editorial Blanecolor Ltda.

(2013) OSPINA, María. Miradas De Jóvenes Investigadores: Construcción Social, Niñez, Desplazamiento Forzado Y Socializaciones: La Subjetividad De Niños Y Niñas En El Conflicto Armado Colombiano: Una Construcción Social.ISBN digital: 978-958-8045-26-9.

(2005) PAZOS,Álvaro. "El otro como sí-mismo. Observaciones antropológicas sobre las tecnologías de la subjetividad", en Revista de Antropología Iberoamericana, Noviembre-Diciembre.

(1994)Política Pública Nacional De Primera Infancia "Colombia por la Primera Infancia", Documento Conpes social. República de Colombia § 8 de febrero

(2008) ROUSSEAU, Jean Jacques.El Emilio. (1972)México: Universidad Veracruzana.

(2012) SALCEDO, Hernando. Epistemología o filosofar sobre la ciencia. Medellín: Ediciones Unaula.

(2009)SIERRA, Álvaro. Et al. Niños vinculados al conflicto cubrimiento periodístico responsable. Introducción, cap. 1 y 2. Bogotá: Medios para la Paz MPP, Unión Europea y Fundación Colombia Multicolor.

(1994)VASCO, Carlos. Tres estilos de trabajo en las ciencias sociales: Comentarios a propósito del artículo Conocimiento e Interés de JurgenHabermas. Bogotá: CINEP

(1990)ZULETA, Estanislao. "Sobre la Guerra". En:

http://catedraestanislao.univalle.edu.co/SobreGuerra.pdf 